\title{
De Piacenza a la corte española: Giacomo Bonavia. Entre Madrid y Aranjuez, arquitectura y ciudad
}

\author{
Diego SuÁrez Quevedo \\ Universidad Complutense de Madrid. \\ Departamento de Historia del rte II (Moderno) \\ disuarez@ucm.es
}

Recibido: 17-02-2014

Aceptado: 26-09-2014

\section{RESUMEN}

Se trata de revisitar y perfilar la actividad y aportaciones de Giacomo Bonavia al servicio de la corte española, primeramente en Madrid en función de los encargos, por más que fueran nominales, del infante Luis Antonio de Borbón, bajo el control y las ambiciones de su madre la reina Isabel de Farnesio, y luego como un decisivo profesional en la conformación de Aranjuez como una ciudad cortesana para Fernando VI y Bárbara de Braganza.

Palabras clave: Giacomo Bonavia. Vigilio Rabaglio. Filippo Juvarra. Madrid. Aranjuez. Infante Luis Antonio de Borbón. Isabel de Farnesio. Annibale Scotti. Fernando VI. Bárbara de Braganza.

\section{From Piacenza to Spanish Court: Giacomo Bonavia. Between Madrid and Aranjuez, Architecture and City}

\begin{abstract}
It's a matter of establishing profiles ans revisiting the activity and the contribitions of Giacomo Bonavia working for the Spanish Court, at first in Madrid in the name of the Infante Luis Antonio de Borbón, under the control and the ambitions of his mother Queen Isabel de Farnesio, and after as a decisive professional in the conformation of Aranjuez as a corteous City for Fernando VI and Bárbara de Braganza.
\end{abstract}

Key words: Giacomo Bonavia. Vigilio Rabaglio. Filippo Juvarra. Madrid. Aranjuez. Infante Luis Antonio de Borbón. Isabel de Farnesio. Annibale Scotti. Fernando VI. Bárbara de Braganza.

Sumario: Bonavia y la iglesia de los santos Justo y Pastor de Madrid. Giacomo Bonavia y Aranjuez. 
Este trabajo responde básicamente a mi contribución al Segundo Seminario Internacional Hispano-Italiano de Historia de la Arquitectura Barroca ${ }^{1}$. Planteado el citado Seminario sobre Arquitectura Barroca, mediante el hilo conductor de la Vigencia o Superación de los Métodos de Análisis Tradicionales, quiero, aún antes de aludir a Giacomo Bonavia (Piacenza: 1700-Madrid: 1759), sujeto protagonista de este trabajo, esbozar unas breves consideraciones sobre los citados métodos de análisis, desde mi punto de vista y sin intención concluyente alguna pero que, de algún modo, entiendo que aquí resultan coherentes por no decir precisas ${ }^{2}$.

Nunca he tenido demasiada confianza en los métodos tradicionales que, en gran medida han propiciado la conformación de una historia del arte como una historia de los estilos y, además, de una manera un tanto lineal. De este modo, todo quedaba pautado y etiquetado, habiendo contribuido a configurar este rígido encorsetamiento una parte notoria de la bibliografía del siglo XX. Todos y cada uno de los métodos ${ }^{3}$ tienen una parte o aspectos útiles y positivos, que si se matizan y fundamentan coherentemente pueden ser válidos en la actualidad, pero en general han sido usados, a menudo con el consiguiente abuso, desde una hegemonía excesiva y excluyente; la validez de un método de análisis estaba en función de la no consideración de otros, en ocasiones ni parcialmente.

So pretexto de abolir las señaladas etiquetas, por otra parte, un sector importante de la bibliografía más reciente, ha optado por acuñar nuevos términos atrayentes que, a modo de titulares periodísticos, actuaran como reclamos, diluyéndose todo casi a renglón seguido, no fundamentando contenidos ni reflexiones vertidas; lo cual ha redundado a menudo en nuevas limitaciones y rígidos encasillamientos.

En cuanto a cultura arquitectónica (que hace lícito aludir a tratados, modelos, lugares, ideas y todo tipo de debates) y el tandem formado por arquitectura y ciudad, con todas sus relaciones, implicaciones y significados (el segundo término como la correlación prioritaria -que no única- del primero), siempre referido al ámbito occidental evidentemente, son parámetros y coordenadas en los que cada vez más "confío", que entiendo comportan un amplio, veraz e importante recorrido a estudiar y sobre los cuales profundizar, y que asimismo tengo en mayor consideración, buscando como aval el correspondiente contexto, la comitencia y sus sentidos y, en su caso, los programas artísticos, sus iniciativas y finalidades.

Urbanismo entendido como mera planificación, trazado y conformación de entes y ámbitos poblacionales, con toda su importancia geométrica y de distribución de inmuebles, rasgos muy destacables entre otros varios derivados de la proyectiva y del ordenamiento urbano al respecto, no resulta suficiente per se, pienso, y no tiene

1 Real Academia de España en Roma [19-21 de mayo de 2011] coordinado por Juan María Montijano García [Universidad de Málaga]

2 Documentar mediante fuentes primarias una obra de arte es algo válido siempre e incluso prioritario que, de cualquier modo, resulta conveniente comprobar; es a la hora de valorar y reflexionar sobre lo que ya tiene un recorrido bibliográfico, en aras de otras propuestas, consideraciones e interpretaciones donde, a mi modo de ver, el absolutismo metodológico ha constreñido sensiblemente muchos estudios.

3 Como intrahistoria o historia en la historia del arte, es como acaso resultan más interesantes e instructivas las metodologías, sus aciertos, luces y sombras en determinados momentos, contextos y en función de obras artísticas de notorio relieve; de este modo, las diversas aportaciones pueden ser mejor perfiladas y valoradas. 
el alcance al que aspira el término ciudad ${ }^{4}$, en plena y total connivencia y coexistencia con la edilicia ${ }^{5}$, tal y como cabalmente debe entenderse en una concepción más amplia, profunda y de mayor espectro donde las funciones, significados, intenciones y pretensiones, complementan y constelan un más rico y plural universo, cultural y humanísticamente hablando. De algún modo, es una tendencia clara hacia una dimensión de la historia del arte como historia cultural que, no sólo diversifica posibilidades y amplía el horizonte, sino que va asegurando y cimentando una saludable interdisciplinaridad, algo que hoy día nos obliga a todos dejando de ser simplemente deseable, en tanto que disciplina de humanidades con valor científico; todo ello con un continuado norte y referente en el contexto en su más amplio sentido ${ }^{6}$.

\section{Bonavia y la iglesia de los santos Justo y Pastor de Madrid}

Con una muy cualificada formación como pintor, decorador y, sobre todo, como consumado escenógrafo, adquirida en su Piacenza natal a partir de la mejor tradición teatral de los Galli Bibbiena, Giacomo Bonavia -Santiago Bonavía en su castellanización- laboraba desde 1734, para la monarquía española, ante todo con afamados diseños, entonces muy estimados y reconocidos, para escenografías en el teatro del Buen Retiro y en la decoración de estancias del palacio de Aranjuez; su labor para la Corona hispana iba a ser su destino definitivo ${ }^{7}$, durante el tramo final del reinado de Felipe V y a continuación bajo Fernando VI, hasta su fallecimiento veiticinco años después ${ }^{8}$.

4 Y ello respecto a ciudades reales, imaginadas, ideales o ideadas, tanto construidas, como pintadas o taraceadas, o trazadas literariamente mediante relatos, sueños o utopías.

5 Calles, ejes urbanos, plazas y cualquier tipo de espacio abierto, con todos sus sentidos, intenciones y significados, quedan incluidos y a tener muy en cuenta.

6 Obviar distinciones entre arte y arquitectura, incluso a nivel de planteamiento inicial o de enunciado, allanaría el terreno, del mismo modo que el uso o aplicación de términos definitorios, de referencia y/ o explicativos, quede a renglón seguido apuntalado, más o menos razonado o, si se quiere, justificado; no dando por válido, en sí y por sí mismo, tal término o, en su caso, tal calificativo. Aquí, por ejemplo, "barroco en tanto que o en el sentido de o en la idea de, resulta un buen inicio en este sentido o en esta vía, cuestión que, de hecho el profesor Montijano perfiló y dilucidó en los preámbulos y presentación de este Seminario. Esto es algo en mí muy arraigado, pues ya aparecía explícitamente planteado en la "Introducción” de mi Tesis Doctoral: “es arquitectura barroca de lo que vamos a tratar en este estudio, y referida al siglo XVII en Toledo. Aludiremos más adelante a su cualidad de barroca, en qué coordenadas y con qué caracteres" [Arquitectura barroca en Toledo: siglo XVII. Toledo, ed. Caja de Toledo, Obra Cultural, 1990, p. 12] Desde otra óptica, aunar o enlazar la obra de arte con la concepción de patrimonio artístico, si su condición y memoria-referente lo avala, resulta asimismo muy enriquecedor en relación a las consideraciones hechas.

7 Vid. TOVAR MARTÍN; Virginia: "Santiago Bonavía. Pintor y decorador en la corte española", actas del I Congreso Internacional Pintura española, siglo XVIII, Madrid, 1998, pp. 131-143; se afirma aquí que Bonavia llega a España en 1728, como ayudante del pintor Giovanni Battista Galluzzi, asimismo piacentino, trabajando al efecto en los Reales Sitios de La Granja; Aranjuez y Buen Retiro.

81759 data de la muerte de Bonavia, es asimismo el año de fallecimiento de Fernando VI, cuyo reinado había iniciado en 1746 , tras el de su padre Felipe V. 


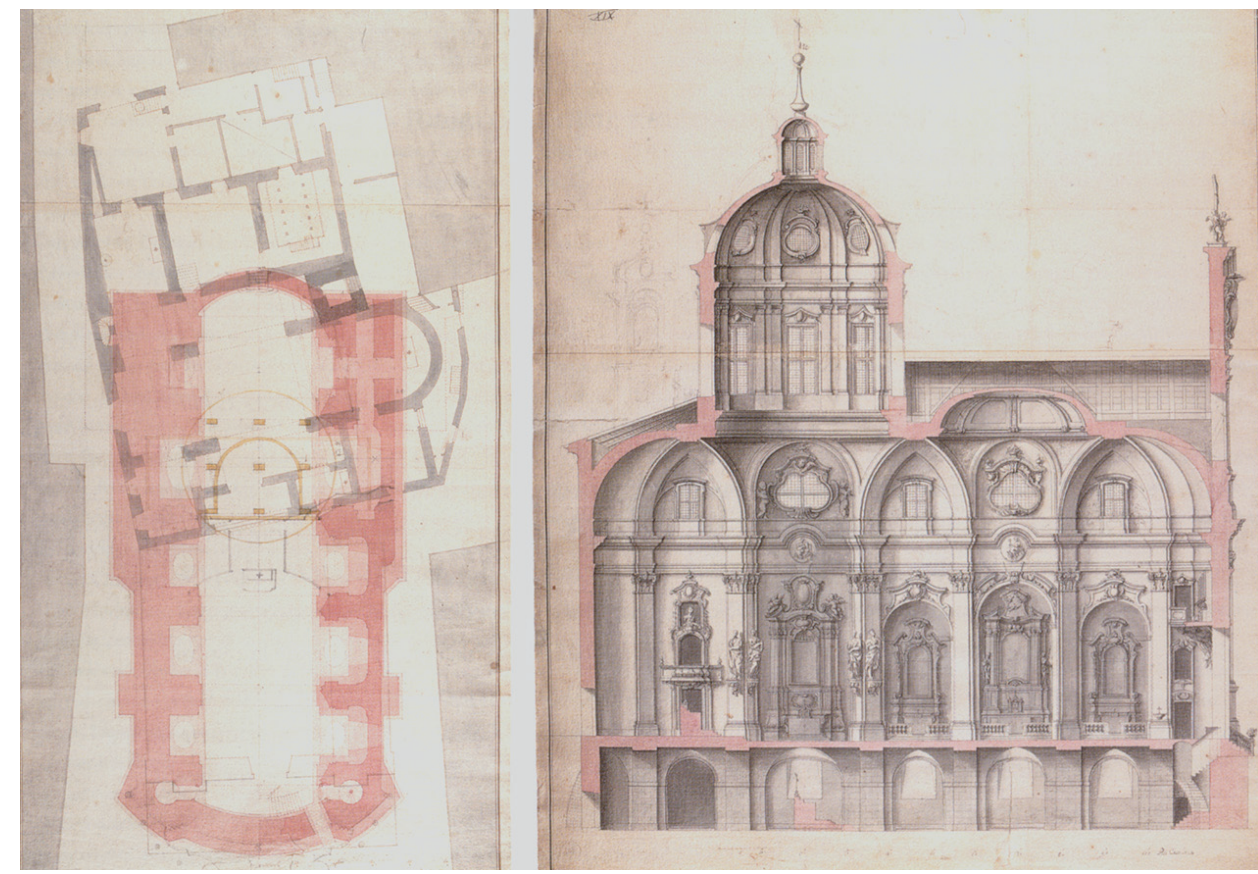

Fig. 1. Vigilio Rabaglio, iglesia de los santos Justo y Pastor de Bonavia (1752-1754).

Bonavia formó parte del denominado "Clan Scotti", junto al arquitecto Vigilio Rabaglio", su hermano Pietro, estuquista y un sobrino de ambos delineante, grupo antagonista de Giovanni Battista Sacchetti, desde 1736 al frente de las obras del Palacio Real Nuevo de Madrid, tras el fallecimiento de Filippo Juvarra, en todos los sentidos $\mathrm{y}$ a todos los niveles referente primigenio de la arquitectura cortesana entonces.

El conde Annibale Scotti, piacentino y en España desde 1717, fue un personaje clave para Bonavia en estos momentos, bajo auspicios de la reina Isabel de Farnesio, "todopoderosa" hasta 1746, año del fallecimiento de su marido Felipe V.

Desde Italia, Bonavia debió venir imbuido, por lo que a arquitectura se refiere, de las novedades y aportaciones de Juvarra en Turín, de las opiniones Guarini versus Juvarra y todos sus contrapuntos, re-encontrando en Madrid a Juvarra y los debates en torno a Sacchetti, sus reducciones, adecuaciones e imposiciones respecto al gran proyecto del Palacio Real ${ }^{10}$ del genial arquitecto de Messina.

9 Las investigaciones más recientes que han contribuido a perfilar la trayectoria profesional de Vigilio Rabaglio, han esclarecido paralelamente la de Bonavia, singularmente en relación con la madrileña iglesia de los santos Justo y Pastor, luego pontificia de San Miguel; vid. BONET CORREA, Antonio: "Vigilio Rabaglio: arquitecto de la reina viuda doña Isabel de Farnesio y del infante cardenal don Luis Antonio de Borbón", en Arquitecturas y ornamentos barrocos. Los Rabaglio y el arte cortesano del siglo XVIII en Madrid. Madrid, Real Academia de Bellas Artes de San Fernando, con el patrocinio de la Caja de Ahorros del Mediterráneo, 1997, pp. 13-37.

10 Al respecto, vid. BLASCO ESQUIVIAS, Beatriz: "Monarquía y arquitectura. La reforma de las obras reales y la construcción del Palacio Real Nuevo", en Arquitecturas y ornamentos... op. cit., 1997, pp. 71-89, 
Annibale Scotti fue asmismo, siempre avalado por Isabel de Farnesio, ayo del hijo de ésta, el infante Luis Antonio de Borbón (1727-1785) que, en 1739, como cardenal $\mathrm{y}$ arzobispo de Toledo ${ }^{11}$ requería, bien que nominalmente, los servicios profesionales de Bonavia -a lo cual enseguida aludiré- pues, contando entonces con sólo doce años, fueron su madre la reina y su ayo-consejero los directamente actuantes e interesados en pro, ante todo, de dar vía, potenciar y prestigiar la carrera eclesiástica del joven purpurado que, no obstante y ahora sí por propia voluntad, renunciará posteriormente a la misma.

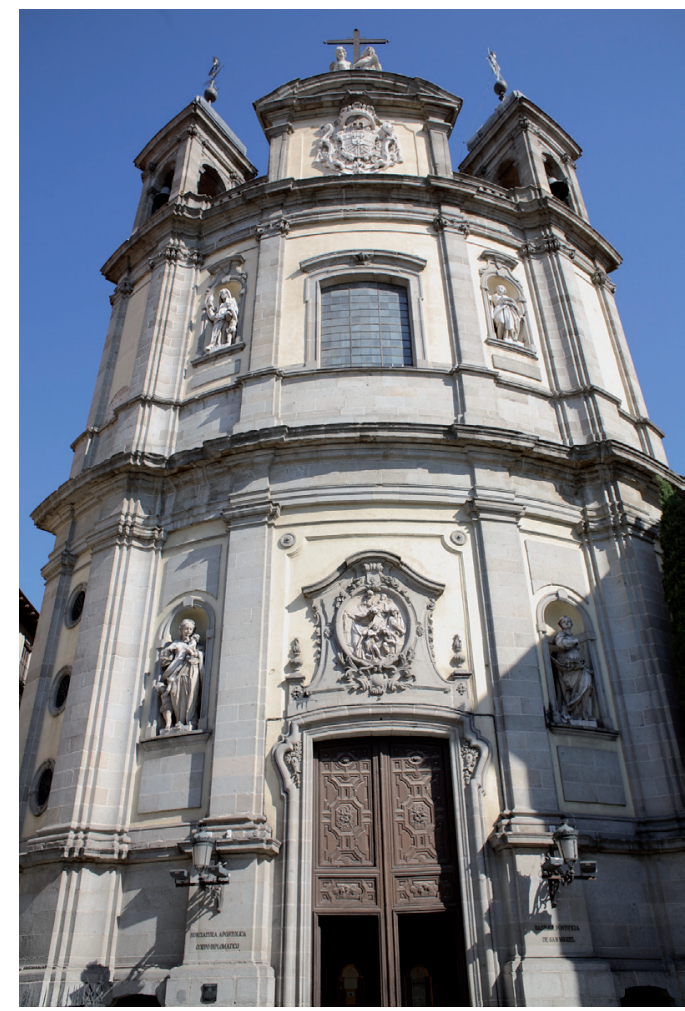

Fig. 2. Fachada de la iglesia madrileña de los santos Justo y Parsor.

En efecto, en 1739 se encargaba a Bonavia el proyecto de una iglesia atendiendo a la advocación de los santos Justo y Pastor y bajo la titularidad del infante-cardenal Luis Manuel de Borbón y Farnesio, a construir en el preciso lugar de otra preexistente y prácticamente en ruinas; unas trazas anteriores al efecto, 1698, de Teodoro Ardemans quedaron sobre el papel. Desde el siglo XIX es la iglesia de San Miguel

con amplia y precisa bibliografía al respecto.

11 Ya titular de la mitra de la catedral Primada, 1735, de modo consecutivo Clemente XII le concedía el capelo cardenalicio con el título de Santa Maria della Scala; renunciará a su estaus eclasiástico, y ahora sí por voluntad propia, en 1754. 
de Madrid y luego, como basílica pontificia, adscrita a la Nunciatura apostólica en España ${ }^{12}$.

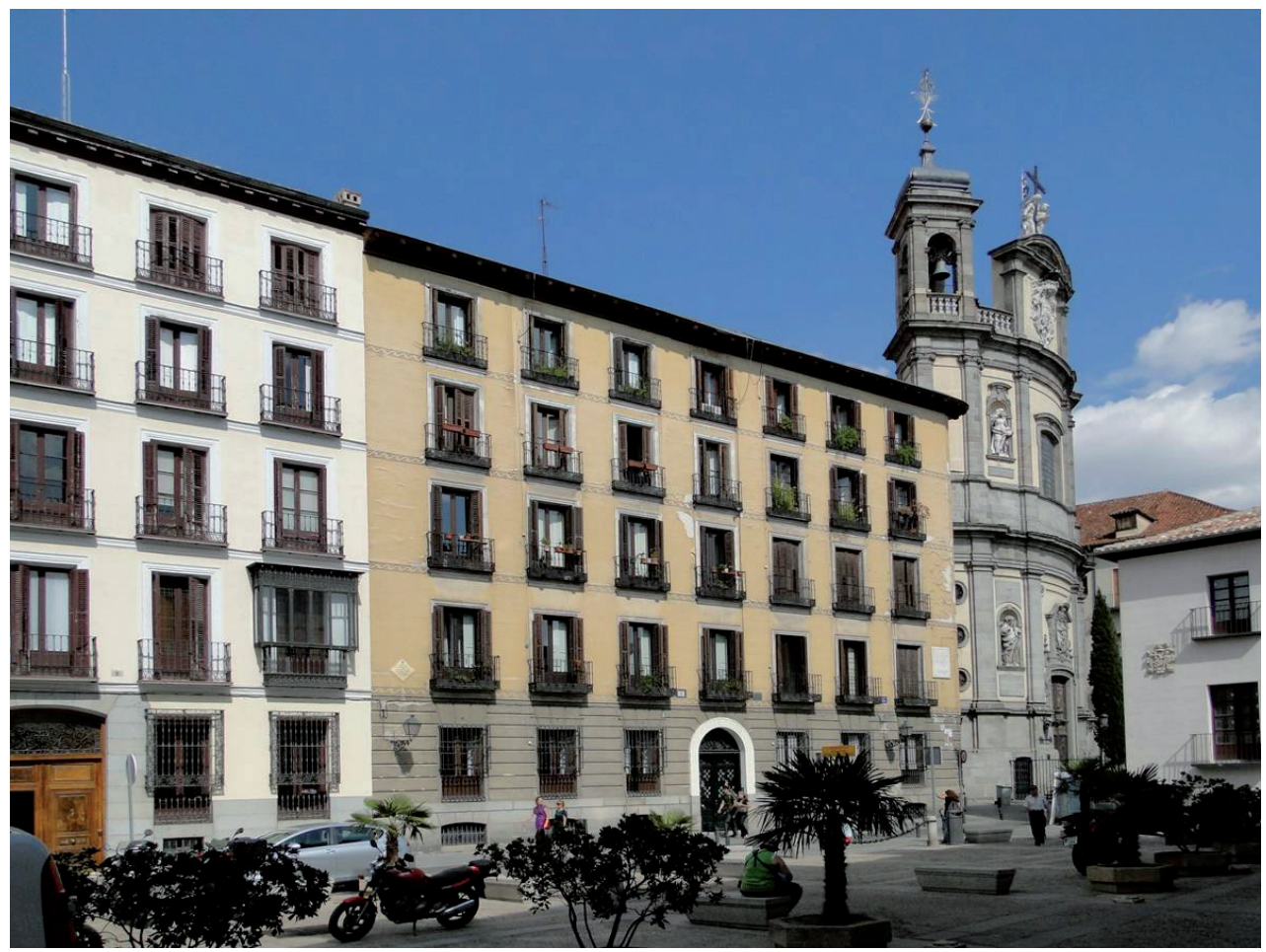

Fig. 3. Vista de la iglesia de las santos Justo y Pastor desde la Plaza del Cordón.

Tras un largo y complejo proceso, entre 1739 y 1754, quedó ultimado el templo madrileño siguiendo el diseño general de Bonavia bajo dirección de Vigilio Rabaglio ${ }^{13}$, que actuó in situ como aparejador y director de obras, aportando trazas parciales, rectificaciones, acomodaciones y variantes contando siempre con la aprobación de Bonavia, desde 1743 concentrado, prácticamente en exclusiva, en las obras del Real Sitio de Aranjuez.

Contrastantes curvaturas presiden los alzados interiores y los varios tramos de la bóveda, en un dinamismo continuado que consigue dilatar y amplificar visualmente

12 La drástica reducción del ábside, 1752-1754, hizo inviable la prevista cúpula y su alto tambor, optándose por otra muy rebajada; ya del siglo XX datan reformas en cripta y presbiterio, y es cuando los retablos de las capillas fueron suprimidos. Es Monumento histórico-artístico nacional desde 1984.

13 Tema estudiado y documentado al completo por SUGRANYES FOLLETI, Silvia: "El proyecto de Santiago Bonavía y la construcción de la iglesia de San Justo y Pastor, de Madrid (1739-1754)", Madrid. Revista de arte, geografia e historia, no 3 (2000), pp. 529-566 e idem: "El proyecto de Santiago Bonavía y la construcción de la iglesia de San Justo y Pastor (1739-1754): Apéndice documental", Madrid. Revista de arte, geografia e historia, $\mathrm{n}^{\circ} 4$ (2001), pp. 279-314; es revisada y comprobada aquí toda la bibliografía desde E. Tormo a los varios trabajos de V. Tovar. 
el espacio interior, lo cual deviene de las combinaciones de refinadas molduras contrapunteadas con soportes de muy estudiada disposición que, a mi entender y pese a la tópica y constante insistencia al respecto, poco o nada -acaso una mera sugestióntiene que ver con el proyecto de Guarini para la desaparecida, 1755, iglesia lisboeta de Santa María de la Divina Providencia.

La convexidad de la fachada ya prevista en la traza de Bonavia, constituyó, en su momento, un auténtico hito en el contexto madrileño, cuyo alzado, obediente a la proyectiva de Vigilio Rabaglio, resulta acaso más interesante, conformando un hastial de textura cambiante y calles simétricas en torno a una más ancha central -petreo lienzo que es eso, convexo sencillamente, aunque haya querido definírsele como borrominesco- de acusados resaltes que los soportes de articulación potencian, y que muestra una marcada división de sus dos cuerpos, mediante la conjunción de una suerte de entresuelo de base del cuerpo alto y el entablamento del bajo que, a su vez, arranca de un alto basamento. Las calles extremas de la estructura están notoriamente resaltadas respecto a las tres centrales, y quedan rematadas mediante sendas torrecillas que alojan las campanas; por su parte, sobre la central, en cuyo cuerpo bajo se dispone la portada de acceso, culmina en un airoso ático asimismo convexo. Fachada eminentemente escenográfica de predominio absoluto de los netos sobre los vanos que, mediante la cuidada disposición de elementos de su alzado y la aludida convexidad de su superficie, alejan cualquier idea o sensación de pesadez.

La fachada se presenta como un organismo casi cerrado, a lo cual coadyuba su convexidad, a guisa de un objeto arquitectónico ensimismado y distanciado, pero de presencia "inevitable" en su entorno que, de este modo, ejerce su específica retórica sin invadir el espacio urbano ${ }^{14}$; las claves de lectura deben cifrarse, a mi juicio, en las ideas de dignidad y prestigio del titular de la iglesia, infante, cardenal y arzobispo primado, mediante este hito arquitectónico en el corazón de la capital del reino.

Arquitectura y ciudad, pues, que así debió entenderse en su momento, una vez concluido el edificio, tratando de despejar el intrincado entorno de la iglesia y conformar dependencias anejas, según un programa nunca completado que por iniciativa del infante Luis Manuel de Borbón contó con Ventura Rodríguez, a partir de una identificación entre comitente y arquitecto que tendrá notoria continuidad ${ }^{15}$.

14 El ensimismamiento y el no invadir el espacio urbano, sí pudieran considerarse, de algún modo, coordenadas borrominescas, al menos como tendencias; bien es verdad que, en su momento, lo eran respecto a determinados planteamientos de Bernini y, sobre todo, de Pietro da Cortona.

15 Los señalados debates derivados de la construcción del Palacio Real Nuevo, tuvieron una suerte de continuidad desde 1746 en la Junta Preparatoria -y desde 1752 en el seno de propia Institución- para la creación de la Real Academia de Bellas Artes de San Fernando; en dicha Junta tuvo un papel importante Giacomo Pavia y contó con una cierta participación de Giacomo Bonavia. José de Hermosilla, Diego de Villanueva y Ventura Rodríguez ya actuante la Academia propiamente dicha, fueron acaso los profesionales más significativos a considerar en sus primeros momentos (vid. RODRÍGUEZ RUIZ, Delfín: “Arquitectura y academia durante el reinado de Fernando VI", en Un reinado bajo el signo de la paz. Fernando VI y Bárbara de Braganza, 17461759. Madrid, Real Academia de Bellas Artes de San Fernando/ Ministerio de Educación, Cultura y Deporte, 2002, pp. 219-243); en esta misma publicacióm (Un reinado...) son destacados, valorados y ponderados muchos aspectos de la construcción de la madrileña iglesia de los santos Justo y Pastor, en SUGRANYES FOLLETI, Silvia: "Italianos y españoles al servicio del programa arquitectónico de los primeros Borbones", pp. 135-146. 


\section{Giacomo Bonavia y Aranjuez}

Coincidiendo, casi de modo estricto, con el propicio reinado ${ }^{16}$ de Fernando VI que, como Bonavia moría en 1759, desarrolló el piacentino en el Real Sitio de Aranjuez, una densa actividad que bien puede enunciarse como ciudad y arquitectura o de dar contenidos al propio planteamiento urbano; personaje clave al respecto en este momento y contexto, fue la reina Bárbara de Braganza y sus ideales que, a su vez, fallecía en 1758.

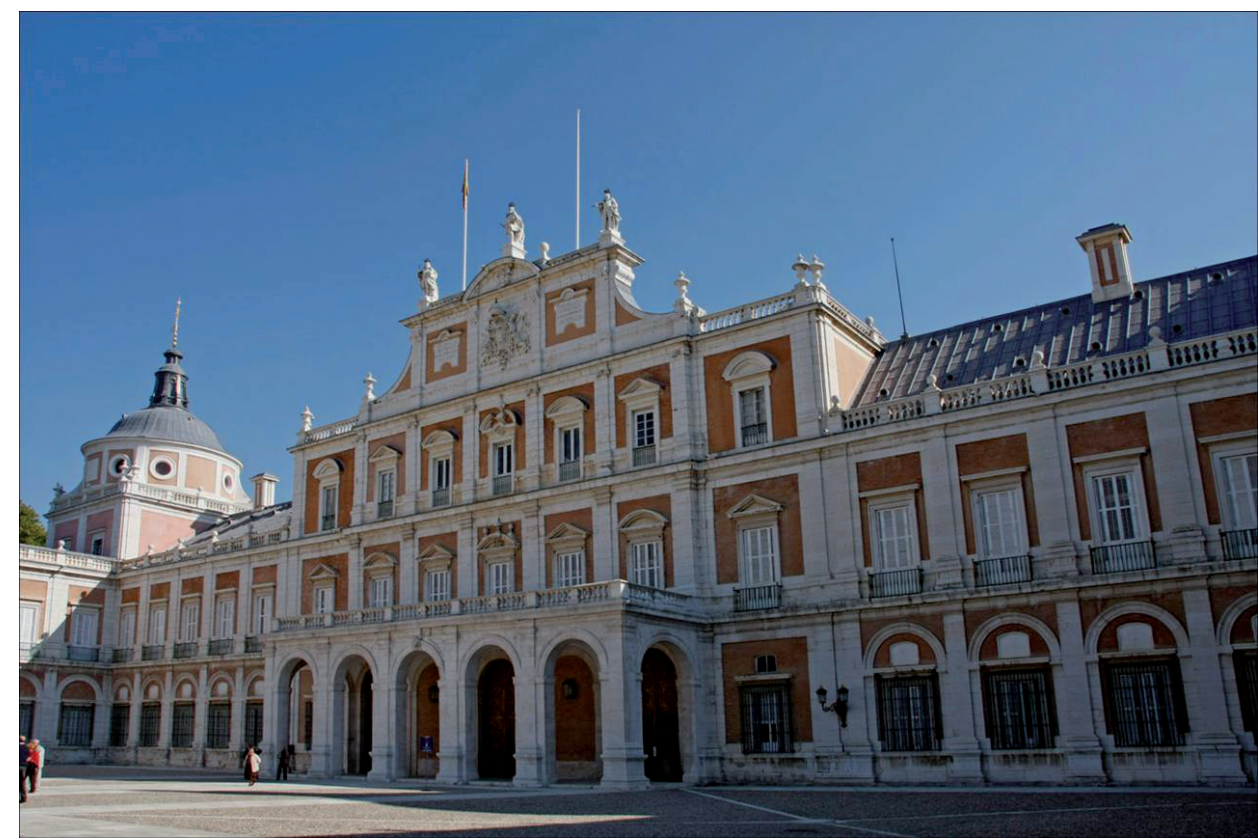

Fig. 4. Palacio Real de Aranjuez, fachada principal.

De manera prácticamente única y desde luego con carácter prioritario, Bonavia aún bajo Felipe V concentraba su actividad en Aranjuez ${ }^{17}$, la cual con Fernando VI, y dadas las envergaduras e importancia de los encargos de la real pareja -es preciso contar al respecto con la reina, sus gustos e intenciones cortesanas- fue total y con dedicación plena. No sabría decir si fue superación, pero sí que supuso un paso importante, no siempre resaltado ni valorado suficientemente por la crítica, desde su condición de escenógrafo y decorador convertirse en tracista de arquitectura, diseñando asimismo la planificación urbana del Real Sitio y, al tiempo, según la amplísima documentación

16 Absolutamente esclarecedor es el estudio de BONET CORREA, Antonio: "Un reinado bajo el signo de la Paz", que es la espléndida introducción a Un reinado..., op. cit., pp. 1-28.

17 El interés de este monarca, y Bonavia aquí ya actuante, se desprende de los compendios burocráticos y ejecutivo, contenidos en Instrucción para el gobierno de las obras del Real Sitio de Aranjuez de 1744. 
conservada atender, como arquitecto principal de Aranjuez, a todo tipo contingencias que in situ supervisaba y controlaba ${ }^{18}$.

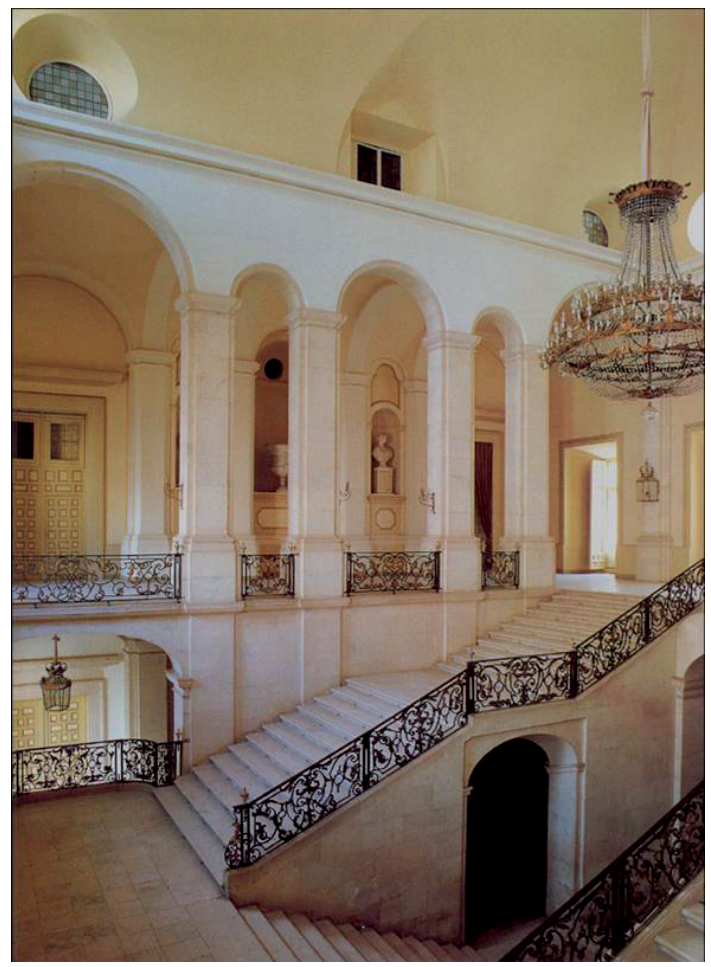

Fig. 5. Palacio Real de Aranjuez, escalera principal.

Por positivo y negativo, 1748 fue un año decisivo para Aranjuez, en función de las obras de Bonavia aquí; un desafortunado incendio asoló ese año al palacio, justo cuando el piacentino ultimaba su espléndida escalera, tras haber dotado al inmueble de fachada, es decir, de un acceso que ya sería el prioritario, atravesado el cual y ocupando todo el espacio hasta el patio del edificio, se situó la espectacular -nunca mejor dicho- escalera. A posteriori, Francisco Sabatini, a partir de 1770, dotará al conjunto de sendos cuerpos o alas perpendiculares al acceso de Bonavia, quedando conformado ante éste un gran cortile d'onore, a manera de patio abierto.

Destacada en el centro del correspondiente hastial de alas más bajas ${ }^{19}$, con sólo dos cuerpos, emerge la fachada del palacio planteada por Bonavia en tres cuerpos y siete

18 Ante todo, remitimos a TOVAR MARTÍN, Virginia: “Arquitectura áulica y urbanismo público en el reinado de Fernando VI”, en Un reinado..., op. cit., pp. 149-162, donde quedan reseñados los varios y amplios estudios de esta autora que contienen abundantes datos documentales, sobre todo del Archivo General de Palacio.

19 De hecho integra la de la izquierda preexistente y, en total simetría, Bonavia diseña la de la derecha. Ni estas alas ni la fachada propiamente dicha, remiten a lo realizado por Bernini en el palacio Barberini de Roma, como alguna vez se ha señalado. 
calles, más un ático que remata las tres centrales; piedra blanca de Colmenar para los elementos estructurales y el rosáceo ladrillo ya utilizado en Aranjuez. Relativamente sencilla e insistiendo en la planitud de los paramentos, armoniza e integra perfectamente lo ya construido del palacio desde el siglo XVI.

Lo más interesante, sin duda, resulta el pétreo cuerpo bajo de la fachada, de mayor altura que los restantes y con cinco vanos en su frente de medios puntos sobre pilares, a su vez de frentes puntualmente articulados con pilastras; cuerpo netamente destacado y avanzando un tanto sobre el espacio previo, con lo que se origina una suerte de terraza sobre el mismo, para conformar un airoso porche a modo de atrio palatino, adecuado preludio y preámbulo, con toda probabilidad de calculado efecto, para su escalera; resulta patente la habilidad con que Bonavia utiliza y maneja en claves escenográficas las estructuras arquitectónicas, y ahora también, ámbitos o espacios.

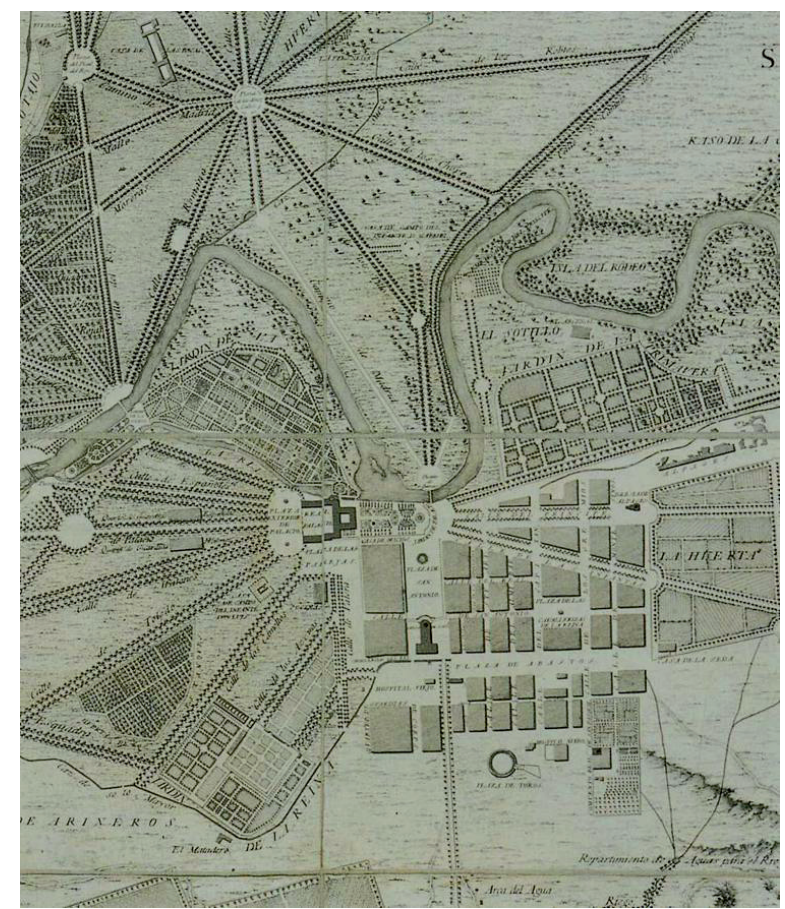

Fig. 6. Plan general de Aranjuez (Bonavia).

La idea de Scotti de ampliar las escaleras principales del Palacio Real Nuevo de Madrid y que se tradujo en el proyecto consecutivo de Sacchetti de 1742, parece haber sido el detonante de la escalera que Bonavia diseñó y construyó en Aranjuez; ésta fue de una envergadura y alcanzó un desarrollo no logrado en ninguna residencia real española hasta entonces ${ }^{20}$, evidenciando la importancia del tema asumido y consus-

20 En su propio ámbito y dadas sus específicas representatividad y connotaciones, a esta escalera podría aplicarse perfectamente el calificativo de una "meta-arquitectura", en un sentido cercano al acuñado y 
tancial al arquitecto italiano y que tanta querencia había tenido siempre en España. El cuidado y control del diseño, que se traduce en el empaque, dignidad y significación de esta estructura, de nuevo, en coordenadas áulico-escenográficas, son aspectos resueltos a la perfección por Bonavia, singularmente en los tramos de arranque, planteados bajo la idea de multiplicidad de entradas convergentes que desembocan en un espacio único y luminoso; la balaustrada de hierro con su ágil diseño, asume completamente su cometido funcional-decorativo y es un elemento constatemente relacionado como de "raigambre francesa", lo cual seguramente es cierto y que asume e integra una vez más con toda soltura el picentino.

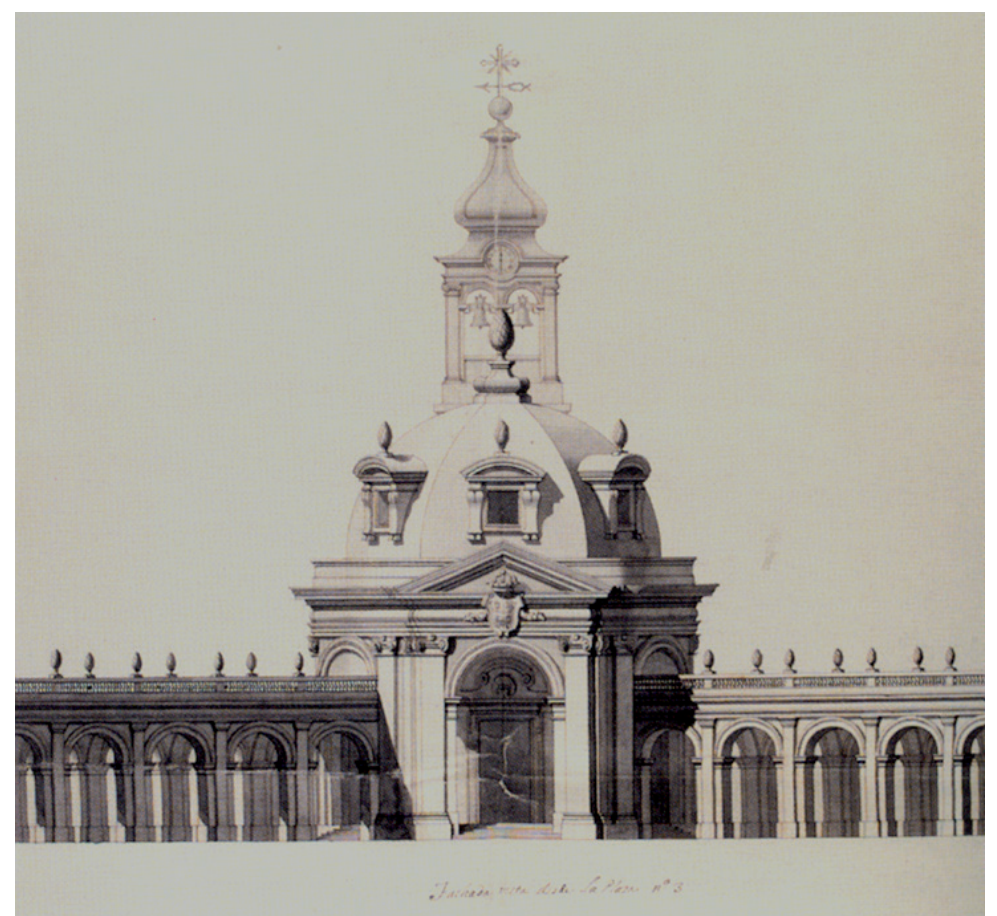

Fig. 7. Iglesia de san Antonio con galerías rectilíneas (Bonania).

Ese mismo año de 1748, Bonavia dando prueba de una actividad incansable y una muy notable organización en pro de un amplio y ambicioso programa ${ }^{21}$, con una dedicación exhaustiva al Real Sitio de Aranjuez y sus obras, no sólo realizaba y remitía a Madrid un completísimo informe de los daños causados por el citado siniestro y lo

comentado por Tafuri [vid. TAFURI, Manfredo: "La arquitectura como metalenguaje: el valor crítico de la imagen", pp. 183-236, capítulo tercero de Teorías e historia de la arquitectura. Madrid, Celeste Ediciones, 1997; traducción de la $4^{\mathrm{a}}$ ed., Roma-Bari, Gius. Laterza \& Figli Spa, 1976], término que podría aplicarse al palacio al completo y su entorno urbe-natura pero de un modo menos convincente.Sí resulta perfectamente coherente en esta línea e ideas el lado menor de la plaza de San Antonio, conformado por la iglesia homónima y sus galerías exteriores, a las que aludiré luego, respecto evidentemente a este amplio espacio urbano abierto.

21 Incluso antes, desde 1746, para algunos estudiosos. 
que era preciso para las reparaciones oportunas en el menor tiempo posible, sino que, asumiendo y dando respuesta a los deseos de Fernando VI, trabajaba ya en la planificación urbana requerida; esto es, una nueva ciudad para la cual, como una de las primeras exigencias al respecto, en 1749, bajo su propuesta, dirección y supervisión, se emprendía la traída de aguas desde los manantiales de Aldehuela, para asegurar el abasto de la futura población. En 1750 ya había completado el plano definitivo de la nueva urbe y se iniciaban de inmediato las obras al efecto.

Sabido es que Aranjuez, según estricta legislación mantenida desde el reinado de Felipe II por la Junta de Obras y Bosques, era un Real Sitio en una dimensión estricta y exclusiva, de Jornada de Primavera y con prohibición absoluta de ser habitado para quien no fuera criado del rey en activo y aquí destinado. Fernado VI, mediante Real Cédula de 1750, abolía tal prohibición con la idea-necesidad de conformar un cualificado ámbito cortesano donde la fiesta, en su más amplio y genuino sentido y significado, pudiera desarrollarse adecuadamente bajo coordenadas de prestigio regio y locus amoenus; esto último quedaba garantizado en Aranjuez, acaso mejor que en cualquier otro Real Sitio en torno a Madrid como capital del reino. Basta evocar al respecto, durante este reinado bajo el signo de la paz, parafraseando esta certera y muy adecuada definición del mismo, a la Real pareja -fundamental aquí la reina Bárbara de Braganza, de exquisita y esmerada educación y su amor a la música-, al eximio compositor y refinadísimo intérprete Domenico Scarlatti y al afamado castrato Farinelli, a las reales falúas surcando plácidamente el curso del Tajo y todo ello con presencia de los precisos cortesanos, adecuados actores al tiempo que espectadores, que ahora sí podían residir en Aranjuez, de eventos lúdico-festivos logrados mediante las más acertadas combinaciones entre artificio y natura, yo diría que a niveles muy altos y cualificados. En un momento dado, integración e interacción artísticas plenas, de manera fluida, en perfecto ensamblaje y, nunca mejor dicho, en total concierto y armonía: ciudad, arquitectura, natura y fiesta cortesana con un punto álgido en la música.

Conformada definitivamente la nueva fachada, como faz y acceso principales del palacio ${ }^{22}$ y en relación directa "sólo" con natura, sin ser condicionada a ninguna otra relación o tensión, quedaba fijada como consecuencia su trasera, el Jardín del Parterre, cuyos límites externos iban a ser el elemento de arranque y referencia del nuevo trazado viario y, por tanto, con un compás o separación entre el ente urbabo y el palacio propiamente dicho.

A partir de las tres puertas externas del citado Parterre de Palacio, organizó Bonavia el despliegue de un tridente de anchas calles de árboles, en dirección a las huertas y cotos del Real Sitio; de facto, el eje más cercano al Tajo ya existía y fue integrado en esta triple estructuración, cuyo vial central enfilaba directamente la iglesia de Alpajés, pequeña construcción preexistente de sencillísima fachada de finales del seiscientos, que Bonavia intentó adecuar mediante el diseño de un hastial curvo entre torres

22 En buena medida, auténtica cara y fachada de todo el Real Sitio y, entonces, de la nueva ciudad de Aranjuez. 
que no llegó a ejecutarse. Sí, en cambio, fueron realizadas las reformas previstas por el piacentino en el interior del templo ${ }^{23}$.

Asimismo a partir del citado Parterre del lado de la Casa de Oficios preexistente, diseñó Bonavia una gran plaza que, a manera de charnela urbana, quedaba planteada como conexión o nexo entre el palacio y su ámbito específico, que así quedaba suficientemente distanciado y con presencia per se, y la nueva ciudad. Plaza marcadamente rectangular, unas tres veces más larga que ancha y, en este sentido, haciéndose eco de los dictámenes vitruvianos sobre las plazas itálicas.

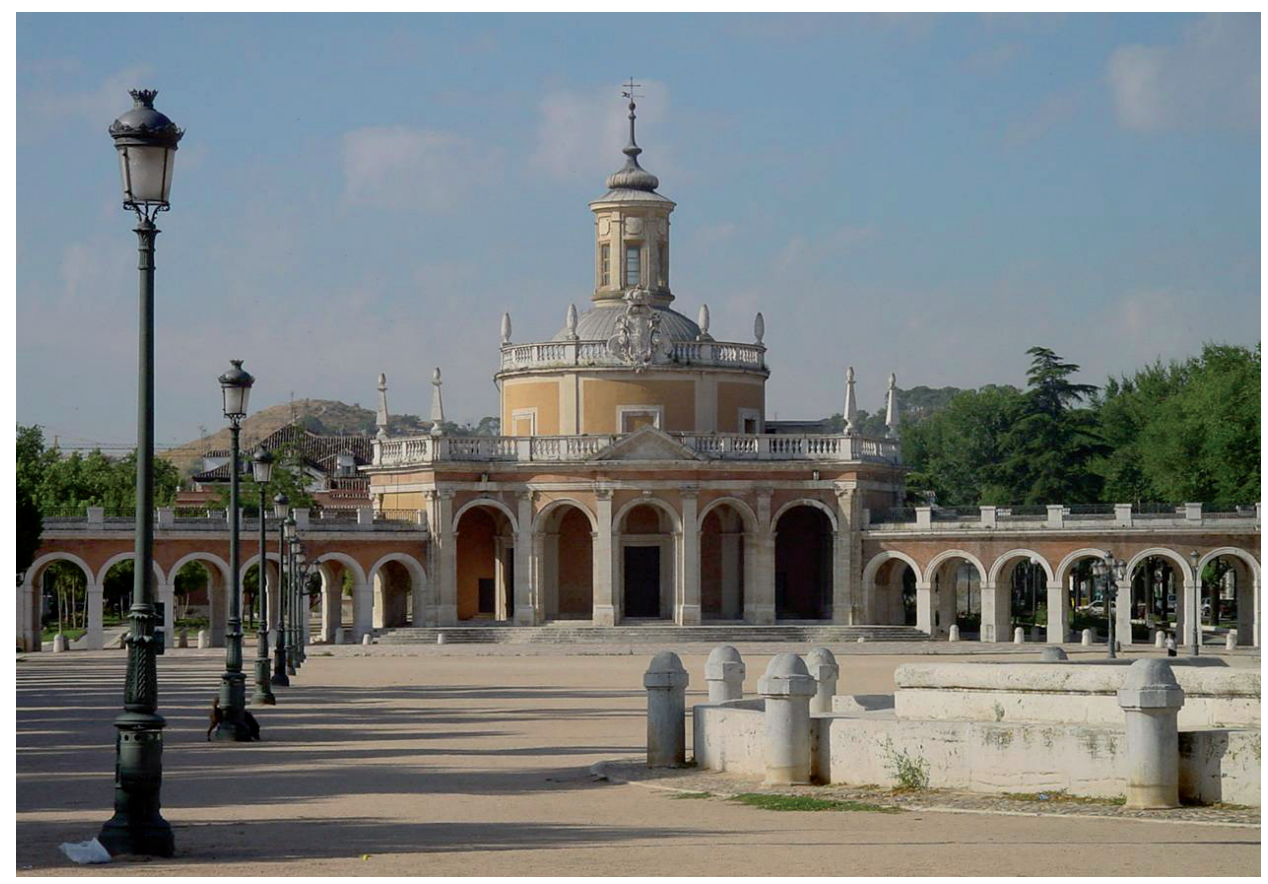

Fig. 8. Iglesia de san Antonio, Aranjuez.

En el lado menor más cercano a palacio, fue dispuesta una fuente ${ }^{24}$, presidida en su momento por la estatua de Fernando VI, que marcaba y significaba el sentido áulico del amplio espacio abierto, en tanto que para el lado menor opuesto proyectó y construyó Bonavia la iglesia de San Antonio, que terminaría por nominar a la plaza. El lado largo derecho, según miramos a la citada iglesia, integraba tras su fachada, tanto a la mencionada Casa de Oficios como a la Casa de Caballeros, denominada usualmente Patio Cuadrado, también construcción anterior a Bonavia.

El tejido urbano dispuesto según una trama reticular, quedó dispuesto entre la plaza y el tridente con un espacio libre en el centro, quedando despejados los flancos

23 Al respecto, vid. TOVAR MARTíN, Virginia: "La iglesia de Nuestra Señora de Alpajés de Aranjuez", Madrid. Revista de Arte, Geografia e Historia, $\mathrm{n}^{\circ} 3$ (2000), pp. 513-528.

24 Remodelada posteriormente en 1760 y 1830 , aparece hoy sin la estatua del rey. 
externos para ulteriores ampliaciones que, de hecho, fueron efectudas casi inmediatamente por Carlos III, pasando a ser el Paseo de Ronda proyectado por Bonavia ${ }^{25}$, una arteria urbana interior.

La trama urbana entre ambos elementos claves y primigenios, esto es la plaza y el tridente, fue disponiéndose mediante una retícula regular, cuidando siempre las alineaciones o rectifilos tanto de los viales secundarios como de sus inmuebles, según una planificación lo suficientemente flexible que, ya en 1759 año de la muerte de Bonavia, permitía incorporar una calle no prevista inicialmente. Por su parte, los terrenos para edificar eran cedidos por el rey, bajo ciertas condiciones que garantizaran el cumplimiento del programa previsto, tanto en claves de puro urbanismo como de atención prioritaria a las ideas e ideales cortesanos que eran básicos entonces.

Como propicio y efectivo vínculo entre el medio urbano y el propiamente palatino, para el que escribe, la plaza de San Antonio de Aranjuez constituyó el gran logro de Giacomo Bonavia, ya que, además de lo señalado, asumió perfecta y adecuadamente las expectativas de los reyes Fenando VI y Bárbara de Braganza, como diáfano espacio abierto a modo de escenario cortesano y lo que podríamos denominar, en esta línea, "plaza de carruajes" que, contaba además, con el idóneo telón de fondo conformado por la iglesia y sus galerías de engarce con los laterales, de tal modo que acaso convendría referirse al mismo, como la auténtica frons scaneae de este foro real y cortesano así configurado ${ }^{26}$.

La rotondità del templo propiamente dicho emerge -y al tiempo es potenciada por- tras el breve atrio y su fachada cóncavo-convexa, de ágil y esmerado diseño, aún más evidente mediante el concurso de las galerías laterales que en la última convergen, rectilíneas en el proyecto de Bonavia, fueron finalmente sustituidas por otras diseñadas por Jaime Marquet, también curvilíneas pero sin gracia ni fuerza, al suprimir las pilastras articuladoras de los frentes de sus pilares que, en la propuesta de Bonavia, constituían auténticas médulas y nervios del alzado de sus galerías en rima y consonancia con las de la fachada, contribuyendo notoriamente además a prolongar el bicromatismo del conjunto, en Aranjuez obviamente la blanca piedra de Colmerar de los elementos estructurales sobre un todo rosáceo.

Desde otra consideración, este Aranjuez de Fernando VI y Bonavia, todo un logro, según queda dicho, en las claves señaladas y en la orientación comentada, fue, de algún modo, único e irrepetible; en efecto, los intereses y proyectos aquí del nuevo rey, Carlos III, fueron bien distintos. Si por una parte, tomando como base y punto de partida lo realizado por Bonavia, amplió la urbe y la dotó de importantes edificios, tales como un nuevo Teatro -no ya el de palacio- afortunadamente recuperado para la ciudad tras su lamentable abandono, fueron, por otra parte, las experiencias de signo Ilustrado las que prioritariamente fue ensayando en Aranjuez este monarca, bajo los

25 Asimismo el piacentino, y para lo que podríamos denominar la "ciudad funcional", llegó a proyectar el Cuartel de Guardias.

26 Configurado como escenario cortesano pero, no conviene olvidarlo, que para Su Majestad Católica, la construcción religiosa dedicada al santo franciscano, no está ni mucho menos fuera de lugar. Esta iglesia de San Antonio de Aranjuez ha sido declarada, en 2003, Bien de Interés Cultural/ Patrimonio Histórico de España. 
dictámenes y orientaciones del Fisiocratismo que potenciaba la Agricultura como referente supremo.

De este modo, al glosado Aranjuez cortesano sucedió el Aranjuez de las ruris deliciis alentado por Carlos III, según la inscripción, que ostenta la data de 1769, que Tomás de Iriarte ideó precisamente para la portada del citado Teatro de la ciudad ${ }^{27}$.

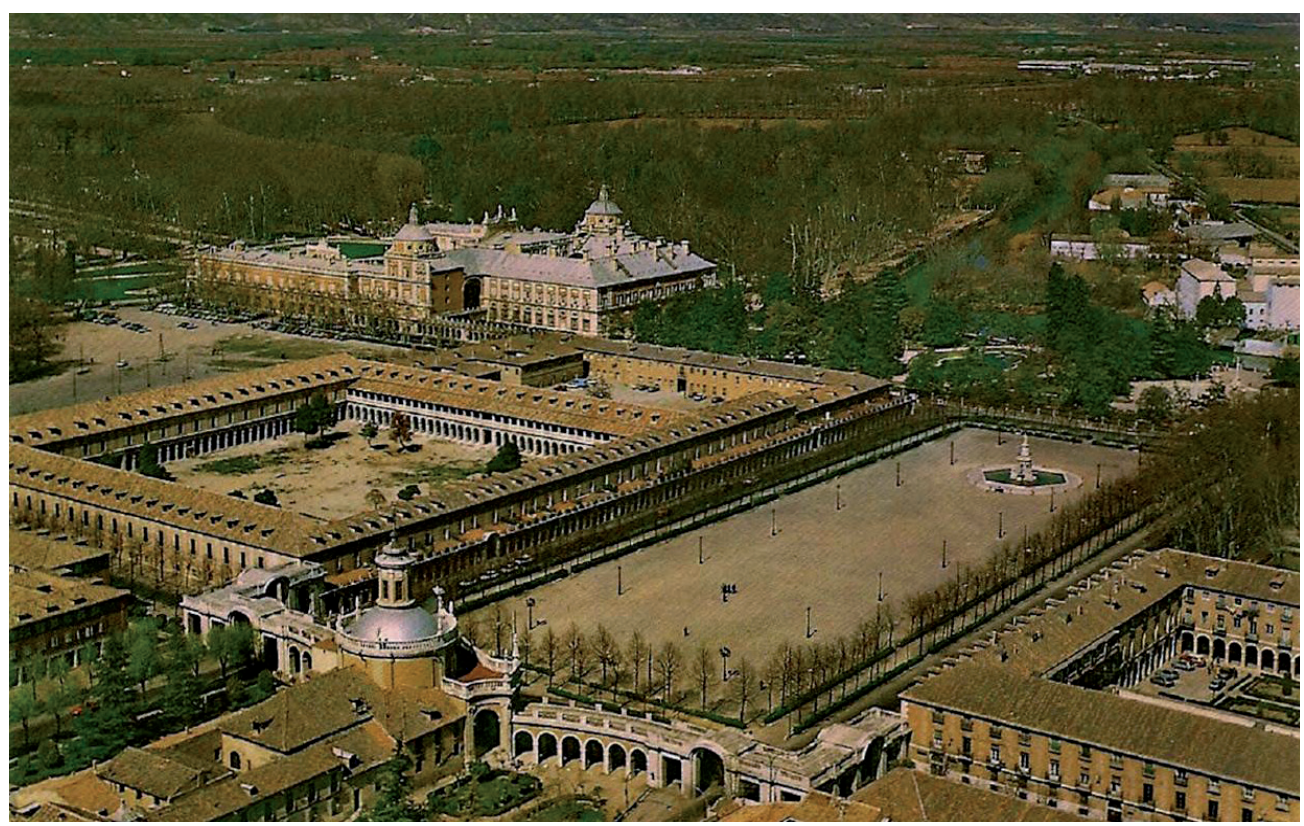

Fig. 9. Vista aérea del palacio de Aranjuez y sus entornos.

27 RURIS DELICIIS ADIECTA URBANA VOLUPTAS/ IUSSUS CAROLO III ANNO MDCCLXIX, es al completo dicha inscripción, a la cual en elogiosos términos no dejará de aludir Antonio Ponz en 1772. 